\title{
INVESTIGATION OF EXPECTATIONS FOR THE AGRICULTURAL PRODUCTION AND FOOD PRODUCTION SECTOR AFFECT OF THE COVID-19 VIRUS PANDEMIC AND MEASURES
}

\author{
Sukru Dursun ${ }^{1}$, Lyudmyla Symochko ${ }^{2,3 *}$ \\ ${ }^{1}$ Konya Technical University, Faculty of Engineering, Konya, Turkey; \\ ${ }^{2}$ Faculty of Biology, Uzhhorod National University, Voloshyna Str.32, Uzhhorod, Ukraine; \\ ${ }^{3 *}$ Institute of Agroecology and Environmental Management NAAS, Metrologichna Str., 12, Kyiv, 03143, Ukraine; \\ *Corresponding Author Lyudmyla Symochko, e-mail: 1yudmilassem@gmail.com;
}

Received June 2021; Accepted July 2021; Published August 2021;

DOI: https://doi.org/10.31407/ijees11.414

\begin{abstract}
The importance of food requirement for the worldwide country is geared towards China COVID-19 pandemic for the agricultural activity and food production in the world with its seasonal fluctuation of foods availably used in domestic food and general products. Initial preparations of the current dispositions, which will also be made food preparations, along with its cultivation in small-producer countries in Asia, then Afrikaans, South America. With its current continuation, it will be designed in a near future as comprehensive, especially in low-income countries in general. It can be predicted that the social and economic damage that can be thought of worldwide can be a very serious effect. It's definitely the case-by-case scenario in the workforce in the fresh fruit and vegetable and animal sectors with the global total revenue completed every day in large chunks of the world and with the design limiting placement. The ongoing pandemic and the person coming from a country selection in the production sector in the country, on the other hand, require the correct health status of the scanner to be taken into account. While the pandemic is occurring in the use by adapting without being collected, it turns out that not being grown, making it economical will not be completed. This study is planned to be evaluated both in terms of health and in terms of economy, by examining and examining what came with the emergence of the pandemic.
\end{abstract}

Keywords: COVID-19, agricultural production, pandemic, food industry, economy, environment. 